\title{
Borehole Rehabilitation: A Case Study in the Dunkwa Mining Town*
}

\author{
${ }^{1}$ A. Ewusi and ${ }^{1} \mathrm{~J}$. Seidu \\ ${ }^{1}$ University of Mines and Technology, P.O. Box 237, Tarkwa, Ghana
}

Ewusi, A. and Seidu, J. (2020), "Borehole Rehabilitation: A Case Study in the Dunkwa Mining Town", Ghana Mining Journal, Vol. 20, No. 2, pp. 11-17.

\begin{abstract}
Rehabilitation works were carried out on boreholes in the Dunkwa Mining town in the Central Region of Ghana. These works were carried out because the boreholes had lost their original yields due to clogging, corrosion and encrustation and had been abandoned for a long time. The cost of drilling a new well and assessing the productivity of the well is $\$ 4,500$ which is more expensive that carrying out rehabilitation works which is cheaper, about $\$ 800$. Also, the initial yields of the boreholes were very high according to the feasibility report which is not a common characteristic of the rocks in the area. Camera inspection followed by rehabilitation, pre and post pumping tests were carried out to assess whether there has been an improvement in their yield after the exercise and that the yield obtained will be adequate for a water supply design. Results show that all the boreholes had an improvement in their yields (57.19 - 259.80\%) after the rehabilitation. It can therefore be concluded that rehabilitation is effective in restoring boreholes to their original yields. Organisations drilling boreholes to communities can take advantage of rehabilitation of the existing boreholes located in the communities which are high yielding, thereby reducing project implementation cost.
\end{abstract}

Keywords: Borehole Rehabilitation, Borehole Yields, Borehole Camera Inspection, Pumping Test

\section{Introduction}

In Ghana, about $81 \%$ of the urban population and $51 \%$ of the rural population have access to basic drinking water sources (Anon., 2017; Cha, 2018). Pollution and mismanagement of surface water resources through small scale and illegal mining has caused a section of the Ghanaian society to resort to groundwater for potable use. The location and occurrence of surface water makes them very susceptible to pollution. Supplying water from surface water sources especially for domestic purposes require treatment which could be very expensive especially in small settlement communities or towns (Akudago et al., 2009). Groundwater continues to serve as a reliable source of water supply to most rural communities in Ghana (Anornu et al., 2009). Groundwater which occurs below the surface in the soil pores, fractures, fissures and other weak geological features or zones is relatively protected from bacteriological contamination and evaporation and can be used for domestic and industrial water supply. The ease of tapping the resource at very close point of need gives it an added advantage over surface water resources. These merits have caused people to rely heavily on groundwater for domestic, agricultural and industrial purposes (Akudago et al., 2009) and as such potable water supplies in rural areas are obtained almost entirely from groundwater sources. Groundwater is normally tapped by drilling water wells.

Water wells require regular maintenance to ensure adequate water flow and continued drinking water safety (Swistock and Rizo, 2020). Rehabilitation involves restoring a well or a borehole no longer in use or with low flow rate back to its initial state and sometimes improving it by using miscellaneous reconstruction treatments or methods.

The Ghana Water Company Limited (GWCL) as part of its plans to provide portable water to the Dunkwa town, decided to restore productive capacities of existing boreholes to be included in the water supply scheme of the town. Borehole rehabilitation works were carried out on some high yielding boreholes in Dunkwa town which is known for small scale mining activities and as such using surface water as sources for domestic water supply is not desirable because of high treatment cost. Many boreholes in the area are very old (some over 30 years) and in very poor conditions, either due to siltation or to corroded casings. This situation can only be improved through cleaning, relining and redevelopment, or, in some cases, by abandoning the old borehole and drilling a new one. Rehabilitation was preferred to the drilling of new boreholes because they are relatively cheaper. In Ghana, a conventional, large-scale borehole redevelopment and test pumping service will cost between $\$ 800$ and $\$ 1,000$ per borehole when contracted to a private company. When done in-house (by purchasing the necessary capital equipment and carrying out the work), this cost may be as low as $\$ 500$ per borehole, though this implies a large cash outlay for the heavy equipment required, and its maintenance over the long term (Nampuzur, 2011). The cost of drilling a new well and assessing the productivity of the well is $\$ 4,500$.

These rehabilitated boreholes were to be included in the design of water supply scheme for the Dunkwa town. The objectives of this paper is to access the effectiveness of borehole rehabilitation and 
determine the total sustainable yields of the boreholes.

\subsection{Geology and Hydrogeology}

The Dunkwa area is underlain by rocks of the Birimian Supergroup which has been folded, metamorphosed and in some places assimilated by granitoids (Fig. 1). The Birimian meta-sedimentary rocks underlying the area are represented by great thickness of isoclinally folded, steeply dipping, alternating shales, phyllites, greywackes and argillaceous beds with some tuffs and lavas. Close to the granitic intrusives, the slates and phyllites have commonly been altered to quartz-biotite schists frequently with garnet and staurolitic-rich bands while the impure sandstones have changed to granulites and quartz schists (Kesse, 1985). The Birimian meta-sedimentary rocks is divided into the following sub-groups:

(i) Upper arenaceous subgroup (massive metasandstone, meta-greywacks and thin beds of metasiltstone)

(ii) Upper argillaceous subgroup (assemblage of phyllite siltstone and their tuffaceous varieties)

(iii) Middle arenaceous subgroup (metagreywacke, meta-siltstone and phyllite assemblage tuffaceous and manganiferous in the middle part)

(iv) Lower argillaceous subgroup (phyllite interbedded with tuffaceous phyllite)

(v) Lower arenaceous subgroup (assemblage of meta-greywacke, meta-sandstone, metasiltstone, phyllite and tuffaceous varieties of these rock types)
Groundwater occurrence in the formation is linked to the fractures beneath the extensive weathered phyllites and clays where confined conditions can be found. Higher yields are obtained when intrusive rocks are encountered during drilling. The area generally has a high groundwater potential.

Weathering in the area is deep and range from (18 35) $\mathrm{m}$ from information on boreholes drilled in the area. The rocks underlying the area have limited primary porosity and the groundwater flow and accumulation are controlled by secondary features such as weathering and fracturing. The development of these features is controlled by the subsurface rock characteristics such as the rock types, tectonic history and the geomorphology, thereby leading to spatial variability in groundwater occurrence and their availability. Average yields of $10 \mathrm{~m}^{3} / \mathrm{h}$ can be obtained from this formation. However, yields of over $30 \mathrm{~m}^{3} / \mathrm{h}$ could be obtained in this formation in situations where intrusive rocks are encountered even though it is not common (Anon., 2009).

Dunkwa is drained by the River Offin which flows from the northwest to the southeast and forms part of the Pra River Basin. The Dia and Sansika streams also flow on the outskirts of the town. Due to 'galamsey' activities being carried out along the banks of these rivers, the water is contaminated and is not being used for domestic purposes. The area experiences two main rainfall seasons with the mean annual rainfall ranging between $1250 \mathrm{~mm}$ and 2000 $\mathrm{mm}$.

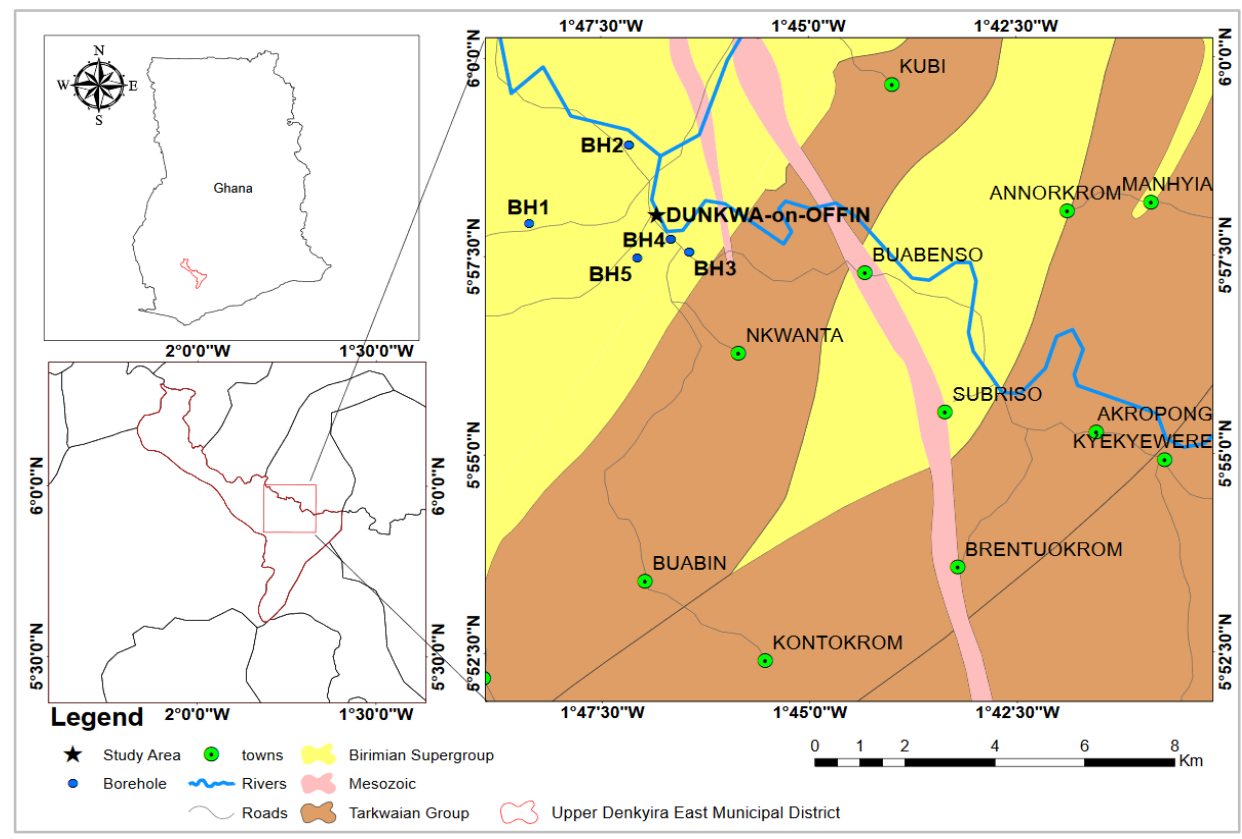

Fig. 1 Simplified Geological Map of Dunkwa Area Showing Locations of Boreholes 


\section{Resources and Methods Used}

\subsection{Camera Inspection}

Camera inspection was carried out to obtain adequate information on the state of the various casings which had been used to align the boreholes and also to ascertain whether the screen used for the construction of the boreholes are clogged. The PASI TC-30 Color Borehole Inspection Camera setup was used (Fig. 2). With its semi-rigid 30 meter fiberglass cable reel with sliding contacts, attached 5.6" TFT LCD color monitor and 12 volt battery, it is portable. The $36 \mathrm{~mm}$ diameter camera head can be easily pushed inside vertical or horizontal holes of small diameter. The TC-30 can be connected to any VCR or any monitor with a video input. The camera unit has an integrated LCD display showing the camera image, camera head distance readout, battery monitor, date and time. The unit also has a digital video recording facility. The rechargeable battery pack and memory storage is sufficient for the camera to record approximately 4 hours of footage.

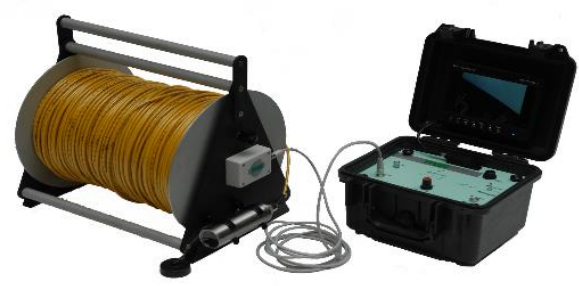

Fig. 2 Borehole Camera and Accessories

\subsection{Pre-Pumping Test}

No historical records on pumping test were available to assess a possible change in specific capacity and determine threshold to evaluate improvement. The pre pumping test data was used as a basis for comparison after rehabilitation.

\subsection{Borehole Rehabilitation}

The rehabilitation de-silts the borehole, opens up the pores of the screen and re-establishes the parameters of the borehole. The boreholes were rehabilitated by redevelopment and brushing of observed biofilming with appropriate chemical solutions which are environmentally acceptable.

The boreholes were redeveloped with compressed air by blowing and surging. During surging the nozzle was moved up and down the screen section for some time to remove any encrustations and dirt on the screen surface. The air pressure is adjusted to be sufficient to remove silt from the screen since too much pressure can break the screen.

\subsection{Post Pumping Test}

A post pump-testing of the boreholes were carried out to evaluate the hydraulic parameters and determine sustainable yields from the pumping test results. The results were also compared with the initial characteristics of the boreholes obtained fro pre pump testing to evaluate the percentage improvement of the boreholes.

\subsection{Sustainable Yields}

Sustainable yield approach (Alley and Leake, 2004) was used because it reserves a fraction of safe yield for the benefit of the surface waters even though there is lack of consensus as to what percentage of safe yield should constitute sustainable yield (Seward et al., 2006).

The Modified Nonequilibrium Equation was used to estimate the maximum sustainable yield that can be pumped from a well in order to develop a pumping water level that does not exceed the maximum allowable drawdown in the well after 300 days of pumping. It is assumed that re-charge occurs during the remaining 65 days of the hydrological year.

\section{Results and Discussion}

\subsection{Camera Inspection}

Some of the reasons why the boreholes were not productive include cracked PVC pipes allowing gravel and silt into the wells, biofilming, silt clogging of screen sections, bail plug/openhole siltation and corroded steel casing. A summary of the observations on the boreholes are presented:

\section{Borehole No. BH 1}

The camera inspection of the Dunkwa BH 1 borehole indicated an open borehole with 10 " steel casing up to $32 \mathrm{~m}$. The internal surface of the steel casing is rusted (Fig. 3). No major fractures were identified in the camera inspection. The borehole has a current depth of $75 \mathrm{~m}$. Water was turbid and mud-laden. The borehole required rehabilitation by redevelopment as the silted zone may have sealed the aquifer zones.

\section{Borehole No.BH 2}

The camera inspection of the Dunkwa BH 2 borehole indicated a composite borehole designed with screen positions located between 26.58 - $30 \mathrm{~m}$ and $36-48 \mathrm{~m}$, and plain PVC elsewhere over a borehole of $52 \mathrm{~m}$ depth. The internal surface of the PVC is stained with thin film of mud. No major 
cracks were identified on the screens in the camera inspection. The borehole required rehabilitation by redevelopment as the mud film may have increased the turbidity of water in the borehole.

\section{Borehole No.BH 3}

The camera inspection of the Dunkwa BH 3 borehole indicated a composite borehole design with screen positions located between 9 - $21 \mathrm{~m}, 27-30 \mathrm{~m}$ and $39-43 \mathrm{~m}$, and plain PVC elsewhere over a borehole of $45 \mathrm{~m}$ depth. The diameter of the borehole is 6". Biofilming was observed on portions of the screen and plain (Fig. 4). Water was slightly sand-laden. The PVC as observed from the inspection showed no indication of compromised integrity.

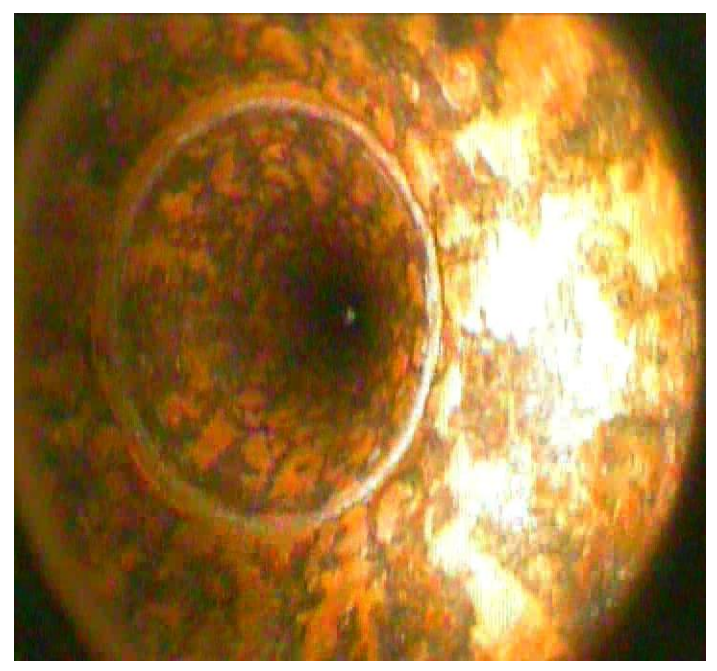

Fig. 3 Rusted Casing Material at BH1

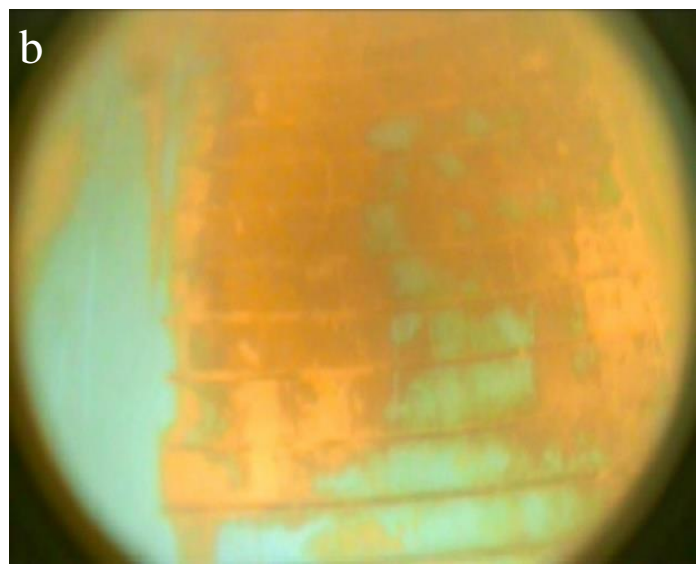

Fig. 4 Biofilming of the Borehole (BH3)

\section{Borehole No.BH 4}

The camera inspection of the Dunkwa BH 4 borehole indicated a composite borehole design with screen positions located between 42 - 54 m, 60 - 66 $\mathrm{m}$ and $70-73 \mathrm{~m}$, and plain PVC elsewhere over a borehole of $75 \mathrm{~m}$ depth. The diameter of the borehole is 6". The internal surface of the PVC is stained with thick film of mud. Biofilming was observed on portions of the screens and plains. Water was mud-laden. The PVC as observed from the inspection showed indication of compromised integrity. The borehole required rehabilitation by redevelopment as the mud film may have sealed aquifer zone and increase turbidity of the water.

\section{Borehole No.BH 5}

The camera inspection of the Dunkwa BH 5 borehole indicated an open borehole with ten inch $\left(10^{\prime \prime}\right)$ steel casing, the end of which was not visible. The internal surface of the steel casing is rusted. Major fractures were identified in the camera inspection. The borehole is currently $48 \mathrm{~m}$ deep. Water was slightly turbid and mud-laden. The borehole required rehabilitation by redevelopment as the muddy zone may have sealed the aquifer zones.

\subsection{Pre-Pumping Test}

\section{Step Test}

A four-step performance test was carried out on the borehole. The purpose of the step-test was to determine the relationship between drawdown and yield for the borehole in the short-term pumping situation, and to select the yield for the constant discharge test. The discharges for the steps were 25 $\%, 50 \%, 75 \%$ and $100 \%$ of the airlift yields respectively. The water from the pump test was finally discharged to a point of overland drainage $100 \mathrm{~m}$ away from the borehole source to prevent a re-circulatory effect. After careful review of the well design as observed from camera inspection, the pump was installed at appropriate depth for each of the five (5) boreholes and this allowed probable dewatering of the upper ingress zones. The static water levels for the pumping borehole at the start of the test were recorded with respect to the established datum. Water level measurements were taken in accordance with recommended guideline time schedule during both pumping and recovery.

\section{Constant Discharge}

The rate for the constant discharge for each of the five (5) boreholes was determined from projecting step-test data over the scheduled 6-hour pumping period and assessing the drawdown. An appropriate discharge rate was then selected. The water level measurements taken were plotted against time on a semi logarithmic graph. The dynamic water level at the end of six hours was recorded (Table 1). 
Table 1 Summary of Pre-Rehabilitation Constant Rate Pumping Test Results

\begin{tabular}{lccccc}
\hline Parameter & BH 1 & BH 2 & BH 3 & BH 4 & BH 5 \\
\hline Measured yields reported in feasibility report (1/min) & 100 & 120 & 120 & 166.67 & 450 \\
Pre-Pumping Test Details & & & & & \\
Discharge (1/min) & 54 & 80 & 90 & 80 & 180 \\
Discharge (m $3 /$ d) & 77.8 & 115.2 & 129.6 & 115.2 & 259.2 \\
Static Water Level (m) & 3 & 15 & 25.5 & 6.5 & 7 \\
6 h Drawdown (m) & 18.52 & 13.06 & 9.5 & 32 & 4.8 \\
Drawdown (m) /log cycle (Constant Discharge) & 6 & 8.5 & 22.2 & 23.5 & 2.2 \\
\hline $\mathbf{Q} / \mathbf{\Delta} \mathbf{s}\left(\mathbf{m}^{2} / \mathbf{d}\right)$ & $\mathbf{1 2 . 9 7}$ & $\mathbf{1 3 . 5 5}$ & $\mathbf{5 . 8 4}$ & $\mathbf{4 . 9 0}$ & $\mathbf{1 1 7 . 8 2}$ \\
\hline
\end{tabular}

$Q$ - discharge, $\Delta s$ - change in residual drawdown over one log cycle

\section{Recovery}

The recovery of each of the five (5) boreholes was monitored over a 3-hour period. At the end the percentage recovery of $95.97 \%, 96 \%, 94.56 \%$ and $98 \%$ were calculated for the boreholes $\mathrm{BH} 1, \mathrm{BH} 2$, $\mathrm{BH} 3, \mathrm{BH} 4$ and $\mathrm{BH} 5$ respectively. The recorded rates of recovery were generally good.

\subsection{Borehole rehabilitation}

The conventional method which was used began with a truck-mounted compressor of the type normally used for borehole drilling, but which far exceeded the compressor requirements for borehole redevelopment. Mechanical treatments including scrubbing, surging water and air jetting were applied to clean the well and to wash the screens which had been blocked. These activities are carried out to ensure that the borehole has been cleaned for flow to occur.

\subsection{Post Pumping Test}

Step Test

The test followed the same as was carried in the pre testing period. The discharges for the steps were 25
$\%, 50 \%, 75 \%$ and $100 \%$ of the airlift yields respectively.

After careful review of the well design as observed from camera inspection, the pump was installed at appropriate depth for each of the five (5) boreholes. The static water levels for the pumping boreholes at the start of the test were recorded with respect to the established datum generally chosen to be the top of casing. Water level measurements were taken in accordance with recommended guideline time schedule during both pumping and recovery.

\section{Constant Discharge}

The rate for the constant discharge for each of the five (5) boreholes was determined from projecting step-test data over the scheduled 24-hour pumping period and assessing the drawdown. An appropriate discharge rate was then selected.

The water level measurements taken were plotted against time on a semi logarithmic graph. From the graph, the Transmissivities were estimated. The dynamic water level at the end of twenty-four hours was recorded. The results obtained from the post pumping test are summarised in Table 2.

Table 2 Summary of post rehabilitation Constant Rate Pumping Test Results

\begin{tabular}{|c|c|c|c|c|c|}
\hline Parameter & BH 1 & BH 2 & BH 3 & BH 4 & BH 5 \\
\hline \multicolumn{6}{|l|}{ Pumping Test Details } \\
\hline Discharge $(1 / \mathrm{min})$ & 120 & 100 & 100 & 100 & 416.67 \\
\hline Discharge (m3/d) & 172.8 & 144 & 144 & 144 & 600 \\
\hline Static Water Level (m) & 2.27 & 14.43 & 22.03 & 4.5 & 5.56 \\
\hline 24 h Drawdown $(\mathrm{m})$ & 24.73 & 17.26 & 12.52 & 48.84 & 5.64 \\
\hline Drawdown (m) /log cycle (Constant Discharge) & 6.45 & 4.72 & 15.68 & 8.17 & 2.77 \\
\hline Percentage Recovery after 12 hours & 96.97 & 100 & 98.56 & 100 & 100 \\
\hline \multicolumn{6}{|l|}{ Calculated Transmissivity } \\
\hline Constant Rate Pumping Test (m²/d) & 4.9 & 5.58 & 1.68 & 3.23 & 45.72 \\
\hline $\begin{array}{l}\text { Estimated sustainable yield at intermitted } \\
16 \text { hours pumping per day }\left(\mathrm{m}^{3} / \mathrm{d}\right)\end{array}$ & 80.0 & 80.0 & 30.4 & 88.0 & 400.0 \\
\hline $\mathbf{Q} / \Delta \mathbf{s}\left(\mathbf{m}^{2} / \mathbf{d}\right)$ & 26.79 & 30.51 & 9.18 & 17.63 & 216.61 \\
\hline
\end{tabular}


There was a significant increase in the discharge of the boreholes. A positive change in discharge from $57.19-259.80 \%$ of the discharges were obtained.

The percentage change in the specific yield of the sampling points was calculated using equation 1 and presented in Table 3, which compares the specific yield before borehole rehabilitation and after borehole rehabilitation for the respective boreholes. The various percentage change after borehole enhancement are shown in Table 3.

$$
\frac{\text { Post-Rehab }- \text { Pre-Rehab }}{\text { Pre-Rehab }} \times 100
$$

It can be observed that, BH4 had the highest percentage change $259.80 \%$ and $\mathrm{BH} 3$ had the least percentage change of $57.19 \%$ after borehole rehabilitation. The mean percentage change for all the five borehole stations is $126.51 \%$ representing an excellent rehabilitation positive change in yield for all the boreholes.

The cost of rehabilitation compared to that of drilling a new well was quite enormous and with these results, it is possible to rehabilitate old high yielding boreholes instead of drilling new ones which might be more expensive and might not obtain high yields as the already existing borehole. Where sharp drawdowns have been recorded, it may be due to dewatering of major water ingress zones. This cannot be absolutely confirmed because detailed drilling data are unavailable to assess water strike zones and specific yield contributions. Current evaluations are based on cumulative yields deduced from airlift yields.

\section{Recovery}

The recovery of each of the five (5) boreholes was monitored over a twelve-hour period. At the end the percentage recovery of $97.97 \%, 100 \%, 98.56 \%$ and $100 \%$ and $100 \%$ were calculated for the boreholes $\mathrm{BH} 1, \mathrm{BH} 2, \mathrm{BH} 3, \mathrm{BH} 4$ and $\mathrm{BH} 5$ respectively. The recorded rates of recovery were generally excellent.

\section{Determination of Safe/Sustainable Yield}

Sustainable yield of an aquifer gives an indication on how much water can be pumped from storage. The sustainable yield of the boreholes in Dunkwa were estimated using the Modified Nonequilibrium Equation (Cooper and Jacob, 1946) to estimate the maximum sustainable yield that can be pumped from a well in order to develop a pumping water level that does not exceed the maximum allowable drawdown in the well after 300 days of pumping. It is assumed that recharge occurs during the remaining 65 days of the hydrological year. The aquifers in the area quite well developed. The existing borehole sources can satisfy a demand of about $678.4 \mathrm{~m}^{3} /$ day for a daily pumping schedule of 16 hours. The combined supply from current assessment of five boreholes is $678.4 \mathrm{~m}^{3} /$ day for a daily pumping schedule of 16 hours. The maximum and minimum yields recorded are 380 and $50 \mathrm{~m}^{3} /$ day (Table 2). Boreholes are generally classified as successful for mechanisation by the Community Water and Sanitation Agency (CWSA) when the yield is greater than $57 \mathrm{~m}^{3} /$ day (40 1/min).

Transmissivity values obtained from the Dunkwa area show that the area can be classified from low to intermediate in terms of groundwater supply potential (Ewusi and Seidu, 2018), which signifies that boreholes are sustainable if it is to be used for local water supply. The pumping test revealed that the five boreholes have transmissivities in the range $(4.9-45.72) \mathrm{m}^{2} /$ day.

Table 3 Summary of the Percentage Changes after Rehabilitation of the various Boreholes

\begin{tabular}{cccc}
\hline & \multicolumn{2}{c}{$\mathbf{Q} / \Delta \mathbf{s}\left(\mathbf{m}^{2} / \mathbf{d}\right)$} & \multirow{2}{*}{ \% Change } \\
\cline { 1 - 3 } Borehole ID & Pre-Rehab & Post-Rehab & 106.55 \\
BH 1 & 12.97 & 26.79 & 125.17 \\
BH 2 & 13.55 & 30.51 & 57.19 \\
BH 3 & 5.84 & 9.18 & 259.80 \\
BH 5 & 4.90 & 17.63 & 83.84 \\
\hline
\end{tabular}




\section{Conclusions}

(i) Pre-emptive catchment protection measures should be instituted through community sensitisation. The boreholes are within town and impact of human activity may be pronounced overtime.

(ii) Rehabilitation by redevelopment and brushing with hydrogen peroxide solution should be carried out at the end of every five years. Special attention is to be given to the screen sections and silted bail plugs.

(iii) Pumping test and water quality analyses should be conducted after redevelopment and specific capacity improvement assessed.

\section{Recommendations}

With the results obtained in the Dunkwa mining town $(126.51 \%)$ positive change on the average for the five boreholes in yields, it is recommended that rehabilitation options are considered in areas where old boreholes with high yields are located to reduce borehole project implementation costs.

Given the numerous assumptions made in the sustainable yield calculations, it is strongly advisable to regularly monitor the pumping water levels in the borehole.

\section{References}

Akudago, J. A., Chegbeleh, L. P., Nishigaki, M., Nanedo, N.A., Ewusi, A, Kankam-Yeboah, K, (2009). Borehole Drying: A Review of the Situation in the Voltaian Hydrogeological System in Ghana. J. Water Resource and Protection, Vol. 3, pp. 153-163

Alley, W. M. and Leake, S. A. (2004), "The Journey from Safe Yield to Sustainability", Ground Water, Vol. 42, pp. 12-16.

Anornu, G. K., Kortatsi, B. K. and Saeed, Z. M. (2009), "Evaluation of groundwater resources potential in the Ejisu-Juaben district of Ghana", African Journal of Environmental Science and Technology, Vol. 3(10), pp. 332-340.

Anon., (2009), Siting and Rehabilitation of Boreholes for the Subsequent Year Investment Programme (SYIP), Unihydro Ltd Technical Report, 25 pp.

Anon., (2017), World Health Organization and United Nations Children's Fund. Progress on drinking water, sanitation and hygiene: Updates and SDG baselines. Geneva. $108 \mathrm{pp}$.

Cha S., Cho, Y., Jiae S. K., Yong J. L., Choi, S., Asuming, P., Kim, Y. and Yan, J. (2018), "Costbenefit Analysis of Water Source Improvements through Borehole Drilling or Rehabilitation: an Empirical Study based on a Cluster Randomized Controlled trial in the Volta Region, Ghana, Global Health Action, Vol. 11(1), 1523303, 10 pp.

Cooper, H. H. and Jacob, C. E. (1946), "A Generalized Graphical Method for Evaluating Formation Constants and Summarizing Well Field History", Am. Geophys. Union Trans., Vol. 27, pp. 526-534

Ewusi, A. and Seidu, J. (2018), "Hydrogeology of the Basin Granitoids in the Sekyere South District of Ashanti Region, Ghana", Journal of Geoscience and Environment Protection, Vol. 6, pp. 252-263.

Kesse, G. O. (1985) The Mineral and Rock Resources of Ghana, A.A Balkema Publisher, Rotterdam, 610 pp.

Nampuzur, R (2001), "Report on Innovations in Borehole Rehabilitation", CWSA/CIDA Community Water Project Upper Regions, Ghana, 14 pp.

Seward, P., Xu, Y. and Brendock, L. (2006), "Sustainable Groundwater Use, the Capture Principle and Adaptive Management", Water SA, 32, pp. 473-482.

Swistock, B and Dana Rizzo, M.S. (2020), "Water Well Maintenance and Rehabilitation", Technical Report, The Pennsylvania State University. 5 pp.

\section{Authors}

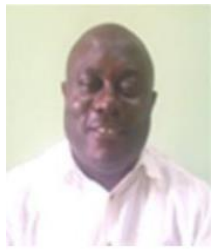

A. Ewusi is an Associate Professor of Hydrogeology at the University of Mines and Technology, Tarkwa, Ghana. He holds a $\mathrm{PhD}$ in Hydrogeophysics and an MSc in Environmental Hydrogeology from the Brandenburg University of Technology, Germany. He obtained a BSc (Hons) Geological Engineering from the Kwame Nkrumah University of Science and Technology (KNUST), Kumasi, Ghana. His research interests are in Groundwater management and Geophysics.

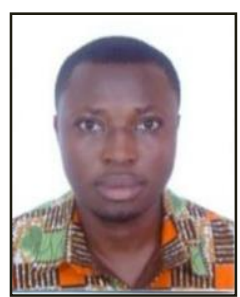

J. Seidu is a Lecturer at the University of Mines and Technology (UMaT), Tarkwa. $\mathrm{He}$ has an MPhil and BSc (Hons) in Geological Engineering from UMaT. His research interests are in Groundwater Studies, Geophysics and Water Resources Management. His current research is application of artificial intelligence techniques to water resources modelling. 